\title{
Article \\ The Respiratory Burst Oxidase Homolog Protein D (GhRbohD) Positively Regulates the Cotton Resistance to Verticillium dahliae
}

\author{
Wanting Huang ${ }^{1,2,+}$, Yalin Zhang ${ }^{1,+}$, Jinglong Zhou ${ }^{1} \mathbb{D}$, Feng Wei ${ }^{1,3}$, Zili Feng ${ }^{1} \mathbb{D}^{\mathbb{D}}$, Lihong Zhao ${ }^{1}$, \\ Yongqiang Shi ${ }^{1}$, Hongjie Feng ${ }^{1,3, *}$ and Heqin $\mathrm{Zhu}^{1,3, *}$
}

1 State Key Laboratory of Cotton Biology, Institute of Cotton Research, Chinese Academy of Agricultural Sciences, Anyang 455000, China; hwanting2020@163.com (W.H.); zhangyalin@caas.cn (Y.Z.); zhouj1510@163.com (J.Z.); weifeng@caas.cn (F.W.); fengzili@caas.cn (Z.F.); zhaolihong@caas.cn (L.Z.); 13619832007@163.com (Y.S.)

2 Zhengzhou Research Base, State Key Laboratory of Cotton Biology, School of Life Science, Zhengzhou University, Zhengzhou 450001, China

3 School of Agricultural Sciences, Zhengzhou University, Zhengzhou 450001, China

* Correspondence: fenghongjie@caas.cn (H.F.); zhuheqin@caas.cn (H.Z.); Tel.: +86-0372-2562280 (H.Z.)

† Wanting Huang and Yalin Zhang contributed equally to this work.

check for updates

Citation: Huang, W.; Zhang, Y.; Zhou, J.; Wei, F.; Feng, Z.; Zhao, L.; Shi, Y.; Feng, H.; Zhu, H. The Respiratory Burst Oxidase Homolog Protein D (GhRbohD) Positively Regulates the Cotton Resistance to Verticillium dahliae. Int. J. Mol. Sci. 2021, 22, 13041. https://doi.org/ $10.3390 /$ ijms 222313041

Academic Editor: Fucheng Lin

Received: 19 November 2021 Accepted: 30 November 2021 Published: 2 December 2021

Publisher's Note: MDPI stays neutral with regard to jurisdictional claims in published maps and institutional affiliations.

Copyright: (c) 2021 by the authors Licensee MDPI, Basel, Switzerland. This article is an open access article distributed under the terms and conditions of the Creative Commons Attribution (CC BY) license (https:// creativecommons.org/licenses/by/ $4.0 /)$.

\begin{abstract}
Verticillium wilt, mainly caused by a soil-inhabiting fungus Verticillium dahliae, can seriously reduce the yield and quality of cotton. The complex mechanism underlying cotton resistance to Verticillium wilt remains largely unknown. In plants, reactive oxygen species (ROS) mediated by Rbohs is one of the earliest responses of plants to biotic and abiotic stresses. In our previous study, we performed a time-course phospho-proteomic analysis of roots of resistant and susceptible cotton varieties in response to $V$. dahliae, and found early differentially expressed protein burst oxidase homolog protein D (GhRbohD). However, the role of GhRbohD-mediated ROS in cotton defense against $V$. dahliae needs further investigation. In this study, we analyzed the function of GhRbohDmediated resistance of cotton against $V$. dahliae in vitro and in vivo. Bioinformatics analysis showed that GhRbohD possessed the conservative structural attributes of Rbohs family, 12 members of RbohD out of 57 Rbohs in cotton. The expression of GhRbohD was significantly upregulated after $V$. dahliae inoculation, peaking at $6 \mathrm{hpi}$, and the phosphorylation level was also increased. A VIGS test demonstrated that ROS production, $\mathrm{NO}, \mathrm{H}_{2} \mathrm{O}_{2}$ and $\mathrm{Ca}^{2+}$ contents of GhRbohD-silenced cotton plants were significantly reduced, and lignin synthesis and callose accumulation were damaged, important reasons for the impairment of GhRbohD-silenced cotton's defense against $V$. dahliae. The expression levels of resistance-related genes were downregulated in GhRbohD-silenced cotton by qRT-PCR, mainly involving the lignin metabolism pathway and the jasmonic acid signaling pathway. However, overexpression of GhRbohD enhanced resistance of transgenic Arabidopsis to V. dahliae challenge. Furthermore, Y2H assays were applied to find that GhPBL9 and GhRPL12C may interact with GhRbohD. These results strongly support that GhRbohD activates ROS production to positively regulate the resistance of plants against $V$. dahliae.
\end{abstract}

Keywords: cotton; Verticillium wilt; V. dahliae; resistance gene; ROS; GhRbohD

\section{Introduction}

Cotton, a primary natural fiber crop, is of great importance to the global textile industry [1,2]. Cotton Verticillium wilt is one of the main dangerous diseases globally, which poses a serious threat to the sustainable development of cotton production [3-6]. Verticillium wilt of cotton is a kind of soil-borne vascular bundle disease caused by Verticillium dahliae, which can cause vessel blockage, leaf yellowing and wilting, and even plant death, mainly resulting in yield and fiber quality loss in cotton [4,7]. Fungus invades from the roots and systematically infects plants, and the number of dormant structure microsclerotia 
directly determines the incidence of the host which is very difficult to control $[6,8]$. In addition, it is very difficult to obtain Verticillium wilt disease-resistant cotton varieties by traditional breeding methods. Thus, it is essential to identify cotton disease resistance genes, especially in the early stage of disease resistance, and incorporate them into elite cotton cultivars. With the development of genetics, molecular biology and genetic engineering, these methods will accelerate progress in the resistance of plants to Verticillium wilt [1]. Ultimately, further understanding is still needed of the key genes in the resistance mechanism and regulation mechanism of cotton against Verticillium wilt [6].

The accumulation of ROS is generally found in systemic disease resistance in many plants [9]. ROS acts as signal molecules, transmitting signals after pathogen invasion, causing plants to produce a series of defense responses such as $\mathrm{Ca}^{2+}$ signaling, kinase cascades, hormone signaling and so on [10]. ROS also has a negative effect in plants, and excessive accumulation of ROS will cause harm, so plants have to tightly regulate the stability of ROS [11]. Plants need to deal with ROS produced by aerobic respiration, including superoxide anion radicals $\left(\mathrm{O}^{2-}\right)$, hydrogen peroxide $\left(\mathrm{H}_{2} \mathrm{O}_{2}\right)$ and hydroxyl radicals (-OH) [12]. Moreover, ROS outbreak, as a conservative immune response, is mainly mediated by NADPH oxidase (NOXs), which is also called Rbohs in plants [13]. NADPH oxidase enzyme generates ROS, with a six-transmembrane-domain structure and C-terminal region, a conservative NADPH- and FAD-containing motif, and a N-terminal region with a two EF-hand motif and phosphorylation site [14]. Mounting evidence indicates that organisms have established their own regulatory system in the process of evolution, and the production of ROS mediated by Rbohs plays a crucial role in plant development, as well as biological and abiotic stress responses [15].

Previous studies have shown that there were ten kinds of Rboh in Arabidopsis thaliana, from AtRbohA to AtRbohJ, among which AtRbohD was the most characteristic, described as a key component of plant defense in Arabidopsis [13,16]. AtRbohD produces superoxide anion radicals in $A$. thaliana in response to intracellular calcium and phosphorylation signals, activating the generation of ROS in the response of Arabidopsis to all pathogens tested [15,17-19]. Previous research has shown that phosphorylation of RbohD at the $\mathrm{C}$ or $\mathrm{N}$ terminal was necessary for plant resistance to pathogens and conserved across plant lineages [20-22]. Moreover, the N-terminal region of RbohD was phosphorylated by a variety of protein kinases, which were synergistically activated by $\mathrm{Ca}^{2+}$ binding and protein phosphorylation to produce ROS, playing various roles in plants and participating in biological and non-biological stress responses [23].

Here, we identified and investigated the role of GhRbohD-mediated ROS in cotton defense against $V$. dahliae. Silencing the $G h R b o h D$ gene compromised cotton resistance to fungus and weakened ROS production, and $\mathrm{NO}, \mathrm{H}_{2} \mathrm{O}_{2}$ and $\mathrm{Ca}^{2+}$ contents, with lignin synthesis and callose accumulation also impaired. Furthermore, the expression levels of resistance-related genes mainly involving the lignin metabolism and jasmonic acid signaling pathways were significantly reduced in GhRbohD-silenced cotton. In contrast, overexpression of GhRbohD improved resistance to V. dahliae in Arabidopsis plants. Collectively, our study provides important evidence illustrating that $G h R b o h D$ positively regulates plant resistance to Verticillium wilt.

\section{Results}

\subsection{Gene Clone and Bioinformatic Analysis of GhRbohD}

In our previous study, a time-course phospho-proteomic analysis of roots between resistant and susceptible cotton lines infected with $V$. dahliae was performed [24]. A respiratory burst oxidase homologue GhRbohD (Ghir_A05G026340) was identified from the plant-pathogen interaction pathway, which may be related to plant resistance to Verticillium wilt. We cloned the full-length cDNA of GhRbohD from cotton cultivar Zhongzhimian 2, which consists of $2793 \mathrm{bp}$, and encodes a protein of 930 aa with six trans-membranes, an N-terminal containing the EF-hands and a conserved C-terminal region containing the $\mathrm{NADPH}$ and FAD binding motifs. In addition, four obviously phosphorylated sites were 
found at the N-terminal of GhRbohD after inoculation with V. dahliae, located in sites 11, 19, and 22 of serine and 17 of threonine.

To investigate their evolutionary relationships, the phylogenetic analysis of the 57 Rbohs from the three cotton species (G. hirsutum, G. raimondii and G. arboreum) and 10 Rbohs from Arabidopsis thaliana were performed by ClustalX2.1 and MEGAX5.0 software. According to homology, the 57 Rbohs in cotton were divided into 7 branches (named RbohA, B, C, D, E, F, H) (Figure 1). There were 12 members in each of RbohA and D, 4 members in each of RbohB and H, 13 members in RbohC, 7 members in RbohE and 5 members in RbohF. G. hirsutum (AD1, upland cotton, HAU assembly) included six kinds of GhRbohD.

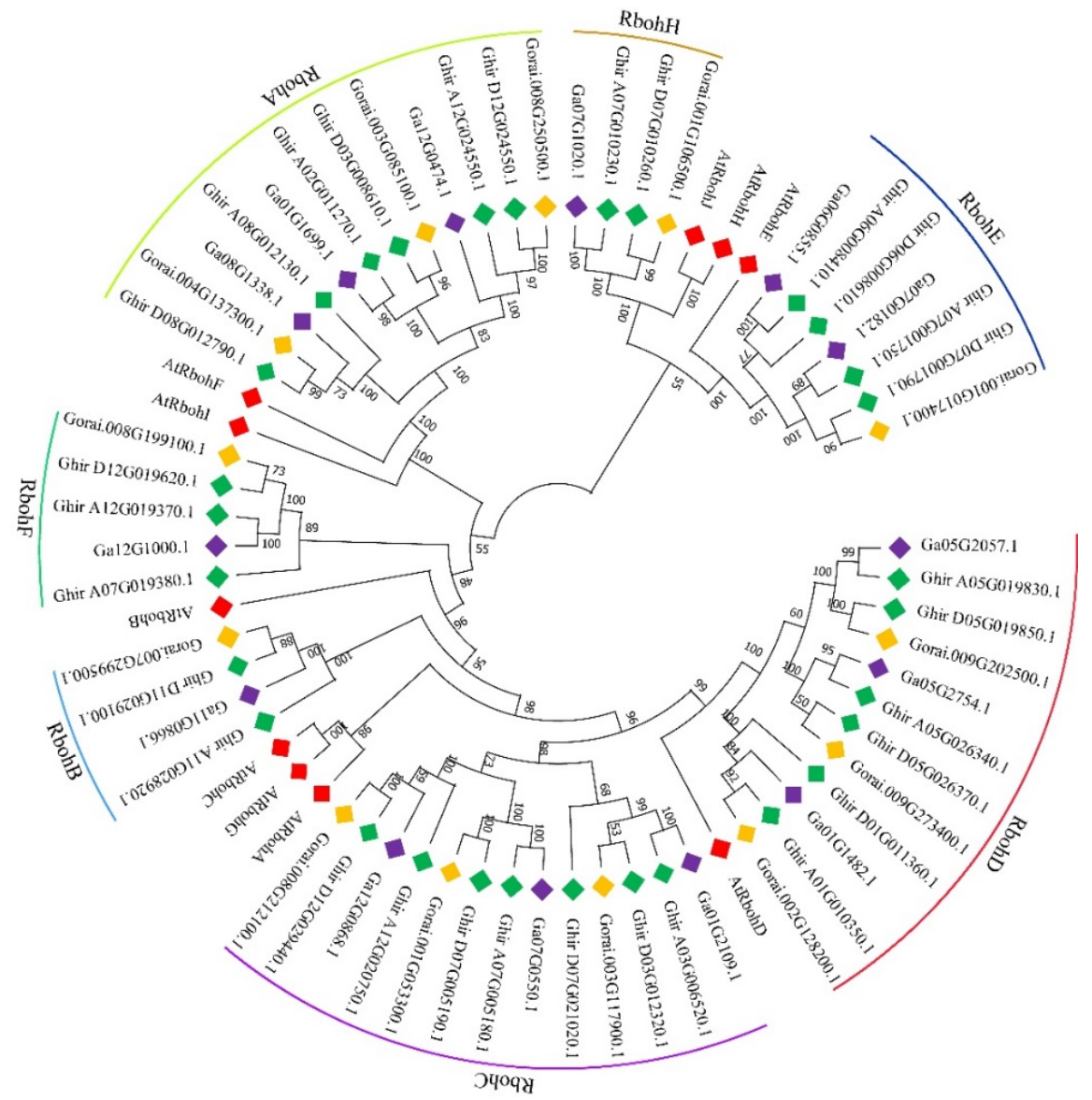

Figure 1. Phylogenetic analysis of Rbohs in Gossypium species. A phylogenetic tree of Rboh proteins from G. arboreum, G. raimondii, G. hirsutum and A. thaliana. The full-length amino acid sequence of Rbohs protein family was compared by ClustalX in MEGA7.0 using the neighbor-joining (NJ) method. Different colored solid squares indicate different genes of the genus Cotton or Arabidopsis.

The conserved motif analysis of the Rbohs family in G. hirsutum showed that the Rbohs homologous genes in G. hirsutum were highly similar and contained at least 10 conserved motifs named motif 1-10 (Supplementary Figure S1). To analyze the exon-intron distributions of the Rbohs genes, the gene structure display server was utilized, and these results indicated that the Rbohs in G. hirsutum had similar gene structure and conserved motifs. Chromosomes localization analysis of Rbohs on G. hirsutum showed that all 30 Rboh genes were distributed in 18 chromosomes. GhRbohD (Ghir_A05G26340.1) was mapped on chromosome A05 (Supplementary Figure S2A). The promoter sequence of Rboh family genes were extracted and cis-acting elements were analyzed to obtain cis-acting elements related to disease resistance, associated with defense and stress, Abscisic acid, Salicylic acid, MeJA, and Auxin (Supplementary Figure S2B). 


\subsection{Expression Pattern of GhRbohD Gene}

The expression pattern of the GhRbohD gene showed that the expression of GhRbohD was generally of high volume in cotton plants (Figure 2A). Among them, the anther, pistil, root, sepal and torus were all about 10 to 20 times, and the bract, petal, and stem 20-30 times. By observing the changes in transcription levels of Rbohs family genes in G. hirsutum inoculated with high pathogenicity (VD991) and low pathogenicity (VD07038) V. dahliae, the expression level of GhRbohD increased by about five times after infection by $V$. dahliae (Figure 2B). The roots of cotton infected with $V$. dahliae strain Vd080 at 0, 1, 6, 12 and $24 \mathrm{~h}$ post inoculation (hpi) were stored, respectively. The expression level of GhRbohD gene in cotton was determined by qRT-PCR. The results showed that the expression level of GhRbohD gene was upregulated rapidly and increased significantly after pathogen infection, especially at $6 \mathrm{hpi}$, indicating that this gene may play an important role in the response of cotton to the stress of $V$. dahliae (Figure 2C). Furthermore, we performed the analysis of the levels of protein phosphorylation modification in recombinant inbred lines' (RIL) susceptible/resistant varieties under pathogenic stress [24]. In susceptible lines (RIL-S), the phosphorylation level after inoculation was 1.5 times compared to without inoculation, and was nearly 2 times in resistant lines (RIL-R) at $1 \mathrm{dpi}$ (Figure 2D), which showed that the phosphorylation level of GhRbohD significantly increased both in susceptible and resistant varieties after infection with $V$. dahliae.

A

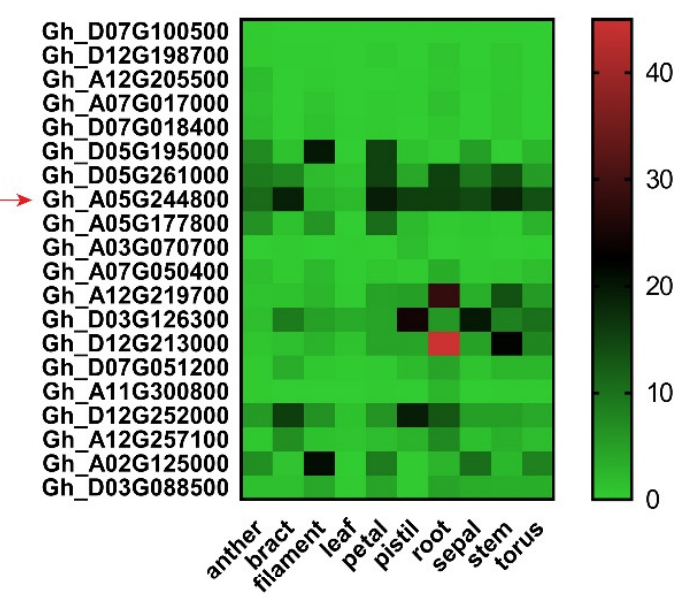

$\mathrm{C}$

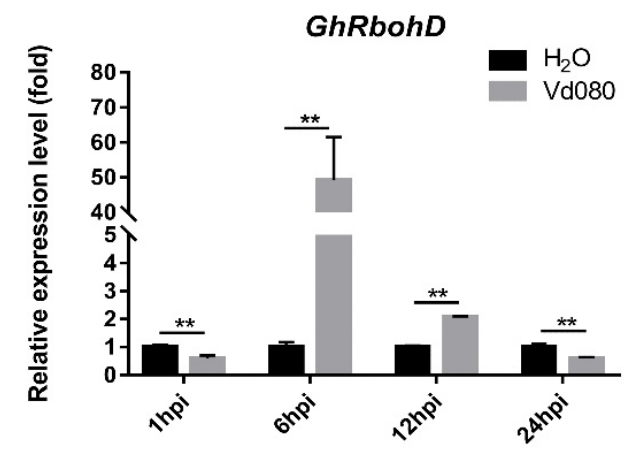

B

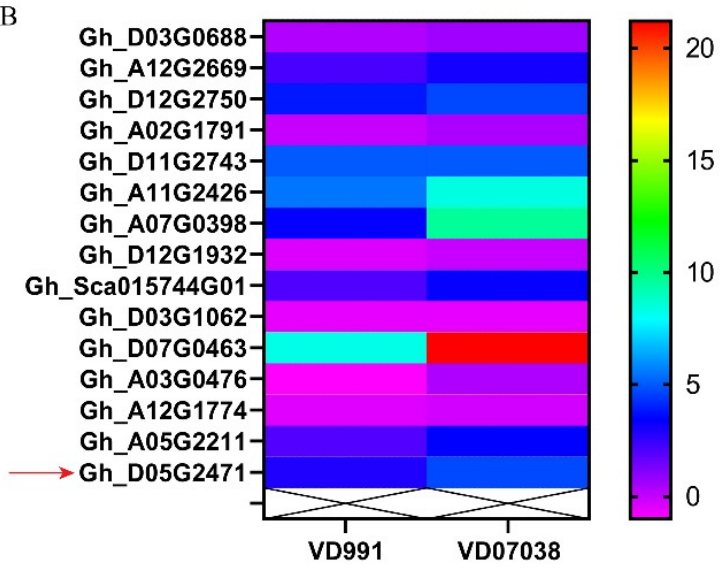

D

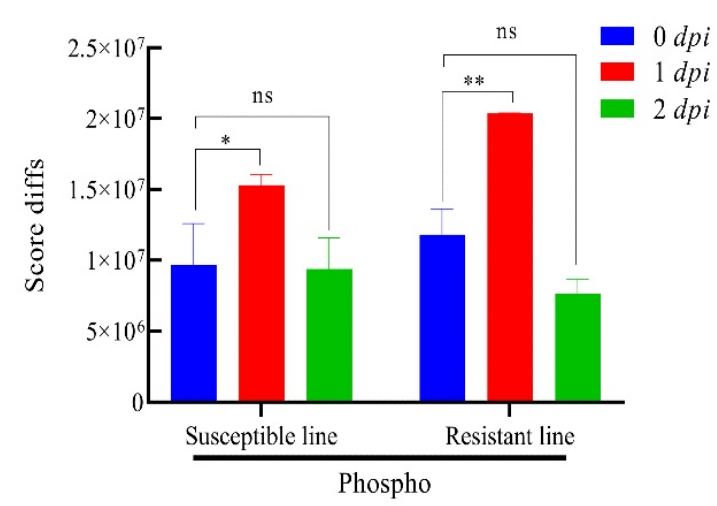

Figure 2. The expression of GhRbohD in cotton under different conditions. (A) Transcriptional level analysis of GhRbohD family genes in various tissues of Upland cotton YZ-1. (B) The transcription levels of GhRboh family genes in G. hirsutum under strong pathogenicity (VD991) and moderate pathogenicity (VD07038) stress. (C) The expression level of GhRbohD in Zhongzhimian 2 under pathogen stress. (D) Analysis of the levels of phosphorylation modification of proteins after translation at different times RIL-R and RIL-S varieties under pathogenic stress [24]. Asterisks indicate statistically significant differences, as determined by Student's $t$-test $\left({ }^{*} p<0.05 ;{ }^{* *} p<0.01\right)$. ns represents no significant difference. 


\subsection{Silencing of GhRbohD Reduced the Basal Resistance of Cotton against V. dahliae}

In order to explore the role of $G h R b o h D$ in defense against $V$. dahliae infection, the leaves of GhRbohD-silenced cotton plants with a positive control gene (GhPDS) showed significant whitening, which indicated that the TRV-VIGS system worked well in cotton plants (Figure 3A). The expression of GhRbohD in the silenced cotton plants was significantly lower compared to the control plants (Figure 3B). Plant disease resistance assessment demonstrated that the yellowing, collapse and even the fall off of leaves in GhRbohDsilenced plants were more serious than those in the control plants, and the DI value of $G h R b o h D$-silenced plants was $59.06 \pm 3.12$ which significantly increased by $53.16 \%$ compared to the control plants $(38.56 \pm 3.61)$ (Figure 3C,D). Compared with TRV::00 plants, the browning degree of vascular bundle in $T R V:: G h R b o h D$ plants showed significant aggravation (Figure 3E). Moreover, lignin synthesis and callose accumulation were detected, and the results showed that the accumulation of lignin and callose in GhRbohD-silenced plants was significantly lower than those in the control plants after $V$. dahliae inoculation (Figure 3F). To further investigate the effects of GhRbohD on plant resistance, pathogen hyphae recovery growth from cutting sections of the infected stem was assayed, and the fungal colonization in TRV::GhRbohD plants were compared further with $T R V:: 00$ plants (Figure 3G). These results indicated that inhibition of GhRbohD gene expression reduced the resistance of cotton against $V$. dahliae.

A

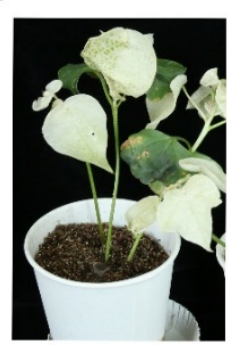

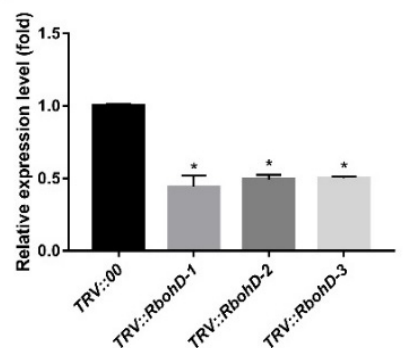

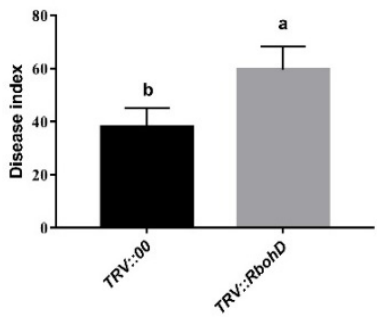

D

$T R V:: 00$

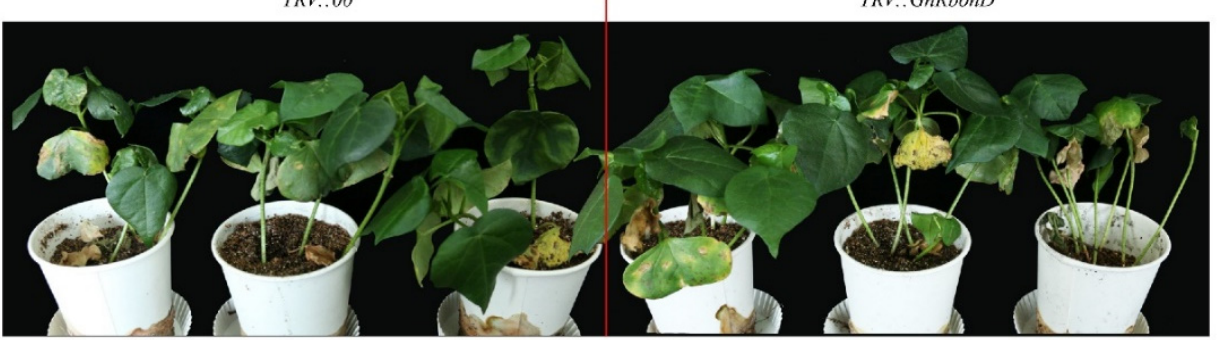

E TRV::00 TRV::GhRbohD F

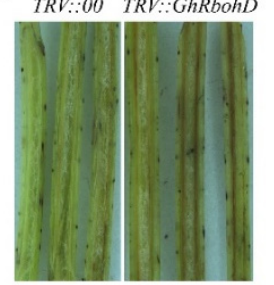

TRV ::00

$T R V:: G h R b o h D$

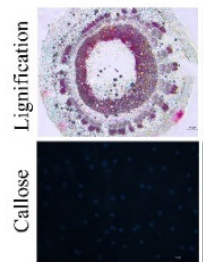

G

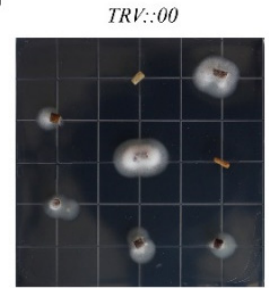

$T R V:: G h R b o h D$

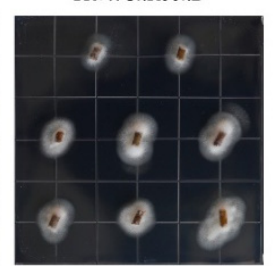

Figure 3. The resistance of cotton to Verticillium dahliae decreased after GhRbohD silencing. (A) TRV::PDS as the positive control for silencing efficiency. Albino phenotype appeared at 12 days after infection. (B) The expression level of GhRbohD in silenced plants and control plants. (C) Assessment of DI for TRV::00 plants and TRV::RbohD plants at $20 \mathrm{dpi}$. (D) The incidence of disease in control and silencing plants. (E) Vascular browning in cotton stem after infection. (F) The xylem stain in stem and callose detection in leaf. (G) Verticillium dahliae recovery assay. Asterisks indicate statistically significant differences, as determined by Student's $t$-test $\left({ }^{*} p<0.05\right)$. Different letters a and $b$ represent significant differences. 
Accumulating evidence indicates that a series of systematic resistance, such as accumulation of ROS, NO, etc., play crucial roles in a variety of biotic and abiotic stresses. $\mathrm{DAB}$ staining demonstrated that the active oxygen burst of GhRbohD-silenced plants leaves obviously decreased compared to that of control plants' leaves (Figure 4A). The $\mathrm{H}_{2} \mathrm{O}_{2}$ contents of GhRbohD gene silenced plants were significantly lesser than that of TRV::00 control plants, with the maximum decrease observed at 12 hpi (Figure 4B). NOA1 is a gene related to NO synthesis. After pathogen inoculation, the expressions of GhNOA1 in $T R V:: G h R b o h D$ plants were generally lower than that in $T R V:: 00$ control plants (Figure $4 \mathrm{C}$ ). Besides, the NO contents in the GhRbohD-silenced samples decreased significantly over the entire time period (Figure 4D). In addition, the calcium ion $\left(\mathrm{Ca}^{2+}\right)$ contents in the silencing GhRbohD plants' roots were significantly lower compared to the control plants, indicating that $\mathrm{Ca}^{2+}$ concentration was positive correlated with GhRbohD activity (Figure 4E).

A

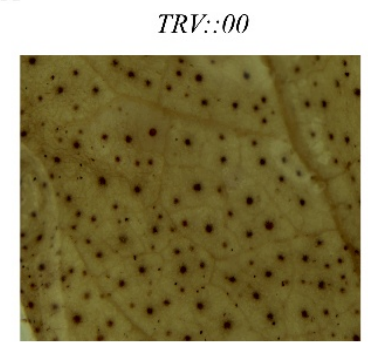

TRV::GhRbohD

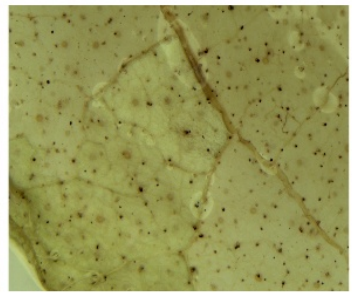

$\mathrm{C}$

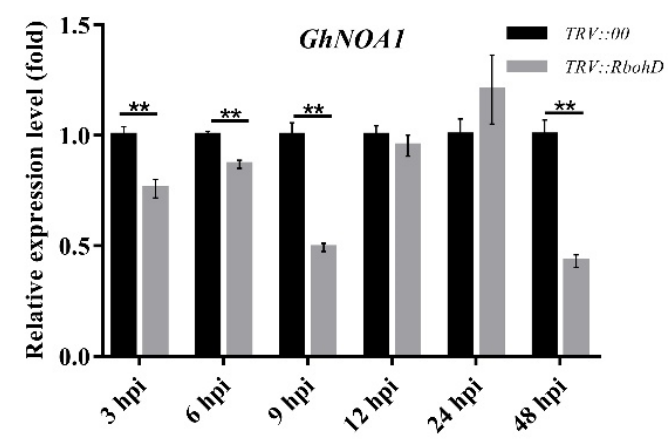

B

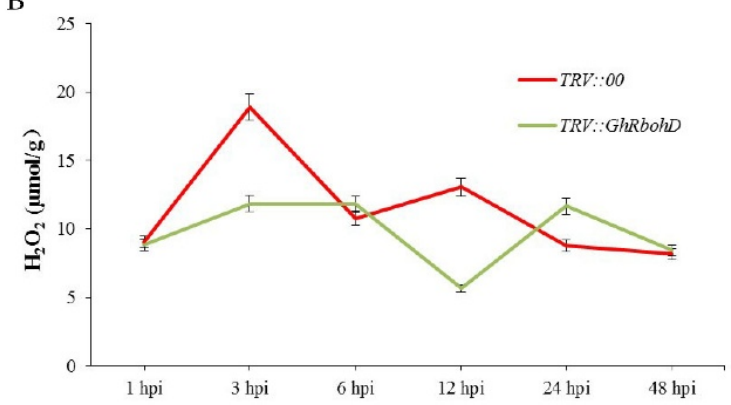

D

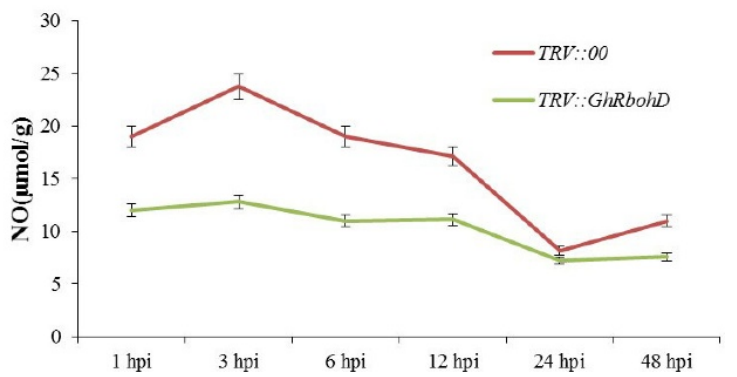

E

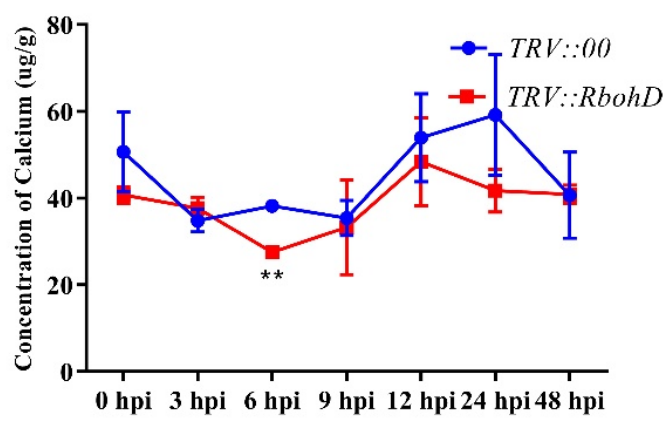

Figure 4. GhRbohD loss-of-function plants has reduced ROS production level. (A) Detection of ROS in cotton leaves. (B) Determination of $\mathrm{H}_{2} \mathrm{O}_{2}$ content. (C) The expression of GhNOA1. (D) Determination of NO content. (E) Determination of calcium content. Asterisks indicate statistically significant differences, as determined by Student's t-test $\left.{ }^{* *} p<0.01\right)$.

\subsection{Silencing of GhRbohD Attenuated the Expression of Resistance-Related Genes}

To further elucidate the effect of GhRbohD on Verticillium wilt resistance in cotton plants, we monitored the expressions of six resistance-related genes, the results showing that the expression levels of these disease resistance-related genes were generally impaired 
in GhRbohD-silenced plants (Figure 5). As key genes of the lignin metabolism pathway, the gene expression of basic chitinase (GhCHI), phenylalanine ammonia lyase (GhPAL5) and cinnamic acid hydroxylase (GhC4H1) was significantly downregulated in the silencing GhRbohD plants compared to the control. In detail, the expression of $\mathrm{GhCHI}$ reached its valley at $9 \mathrm{hpi}$, only about one-fifth of the control, and the same as the expression of GhPAL5. However, the expression of GhPAL5 was continuously suppressed in GhRbohD-silenced plants compared with the control throughout the monitoring process. Besides, in GhRbohDsilenced plants, the expression of resistance-related gene 3 (GHPR3) and hypersensitivity marker gene (GhHIN1) were also suppressed to varying degrees, especially after $9 \mathrm{hpi}$, then maintained stable levels. As an important gene of the jasmonic acid pathway, the expression of GhJaz1 continued to decrease and reached its lowest value at $48 \mathrm{hpi}$, accounting for just one-sixth of that of the control.
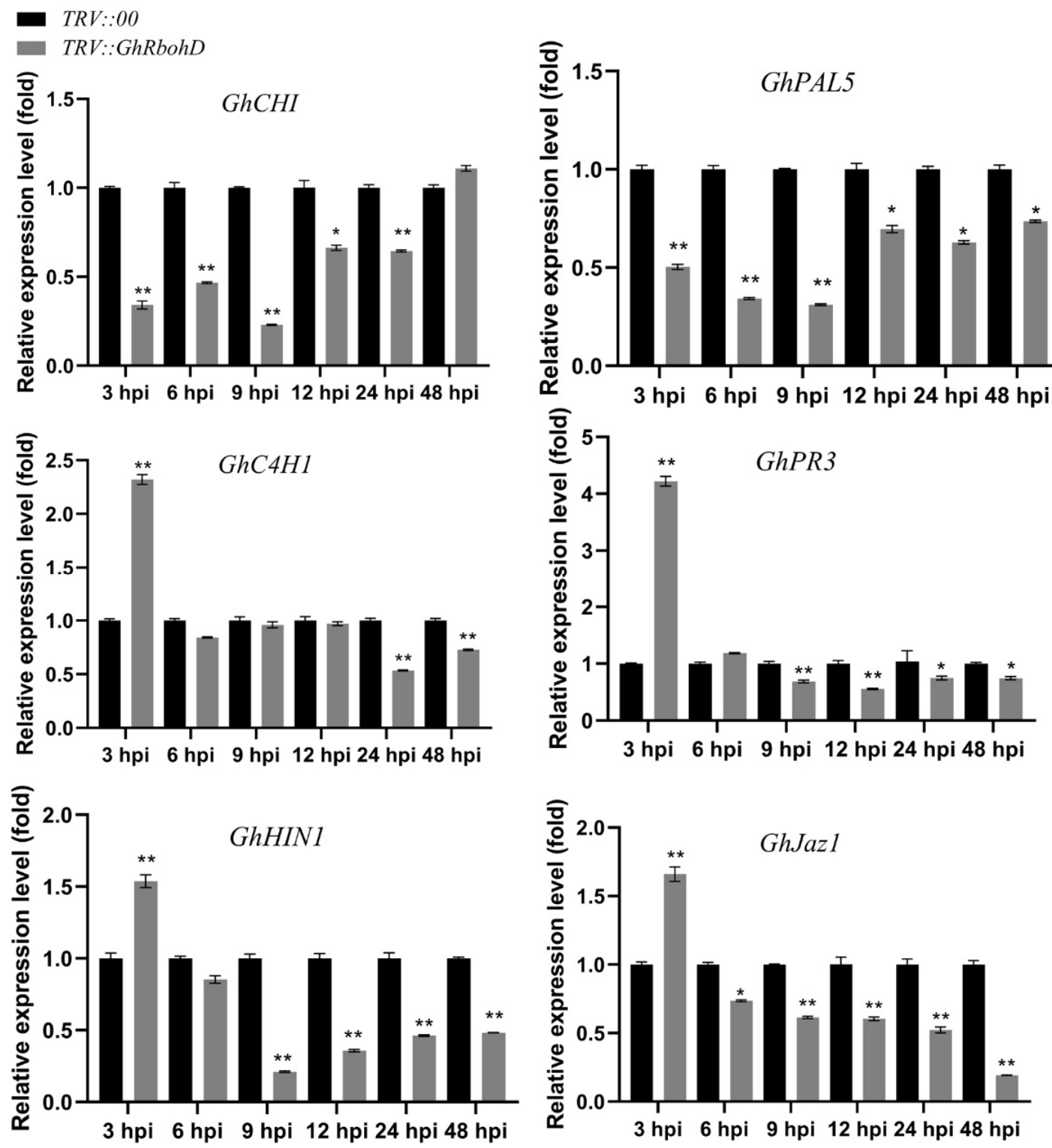

Figure 5. Expression of disease-resistant genes in GhRbohD silencing and control plants. Error bars represent the standard deviation of three biological replicates. Asterisks indicate statistically significant differences, as determined by Student's t-test $\left({ }^{*} p<0.05 ; * * 0.001\right)$. 


\subsection{Overexpression of GhRbohD Enhanced Resistance to V. dahliae in Transgenic Arabidopsis}

To further detect whether $G h R b o h D$ confers resistance to $V$. dahliae, an overexpression strategy in Arabidopsis plants was used. We constructed the overexpression vector of GhRbohD and obtained the transgenic Arabidopsis plants by floral-dip method. Three methods were used to identify homozygous GhRbohD-overexpressing transgenic lines, including 0.1\% kanamycin-screening, PCR and qPCR detection (Supplementary Figure S3). At $14 \mathrm{dpi}$, wild-type (WT) Arabidopsis showed more severe yellowing and wilting than the OE-GhRbohD plants on MS medium (Figure 6A). Besides, plant roots' infection results showed that the amount of hyphae attachment around the roots of WT Arabidopsis were significantly increasing compared to those of OE-GhRbohD plants after $V$. dahliae inoculation (Figure 6B). At $15 \mathrm{dpi}$, the leaves of Arabidopsis began to show wilting and yellowing symptoms, compared to the WT plants, the OE-GhRbohD plants showed much weaker symptoms at $21 \mathrm{dpi}$, and the DI value of OE-GhRbohD plants was $23.05 \pm 1.51$, reduced by $55.09 \%$ compared with WT plants $(51.32 \pm 2.12)$ (Figure $6 \mathrm{C}, \mathrm{D})$. This evidence further supports that $G h R b o h D$ can positively regulate plant resistance to $V$. dahliae.

A

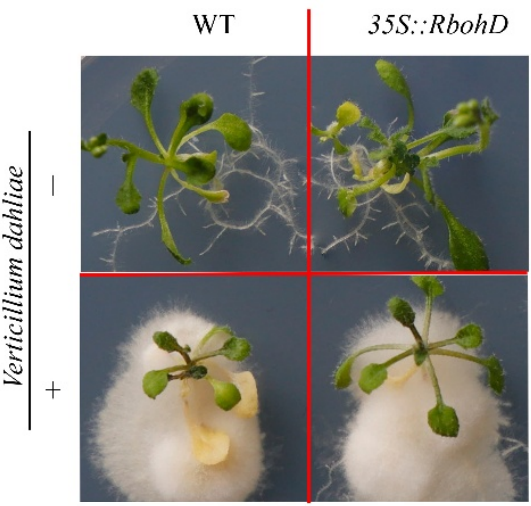

C

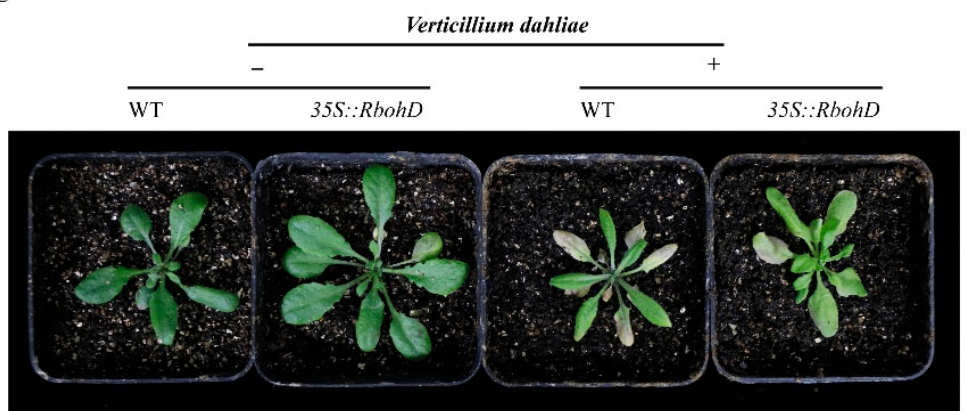

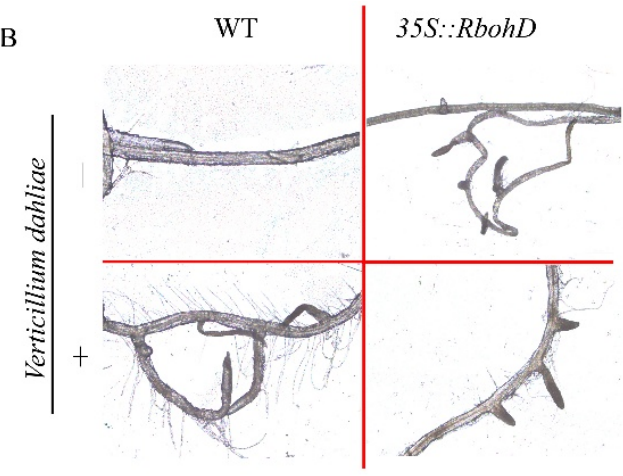

$\mathrm{D}$

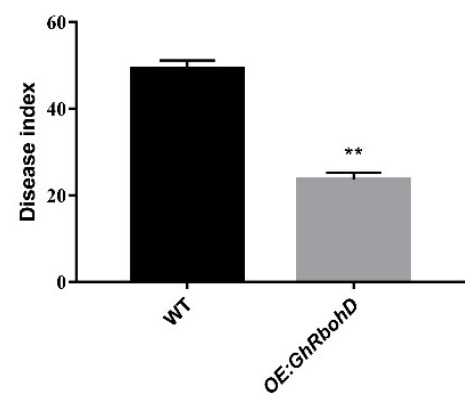

Figure 6. Overexpressing GhRbohD Arabidopsis thaliana enhanced the resistance to V. dahliae. (A) Disease resistance phenotypes of WT and OE-GhRbohD Arabidopsis inoculated with V. dahliae in MS culture medium. (B) The amount of mycelium attachment around the roots. (C) Disease resistance phenotypes of WT and OE-GhRbohD Arabidopsis inoculated with $V$. dahliae. (D) The DI of WT and OE-GhRbohD Arabidopsis. Asterisks indicate statistically significant differences, as determined by Student's $t$-test $\left.{ }^{* *} p<0.01\right)$.

\subsection{Subcellular Localization of GhRbohD}

To gain direct evidence for GhRbohD subcellular localization, tobacco leaves injected with Agrobacterium carrying GFP or GhRbohD-GFP vectors were observed under a confocal laser microscope for fluorescence detection. The results demonstrated that GFP was uniformly distributed in all parts of the cells, indicating normal operation in this experiment, while GhRbohD-GFP was located in the cell membrane and stomata (Figure 7A). Besides, onion epidermal cells were used to further determine GhRbohD localization, which also validated that GhRbohD-GFP fluorescence was observed in the cell membrane before or after plasmolysis (Figure 7B,C). 

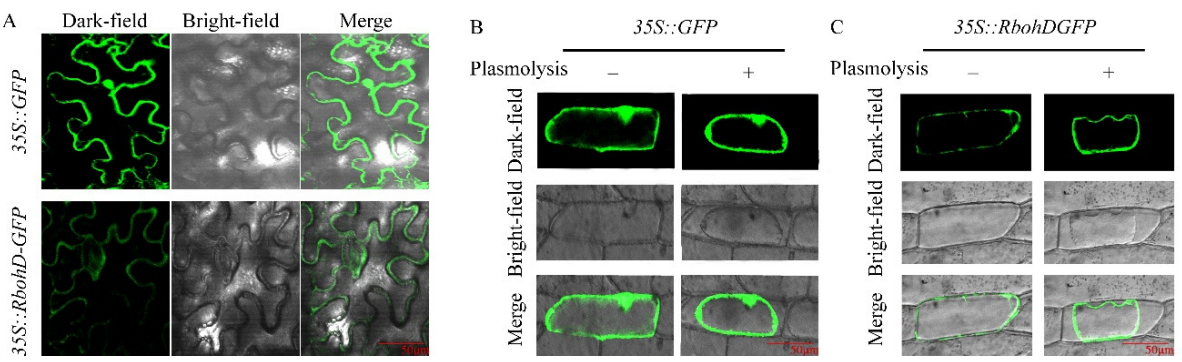

Figure 7. Subcellular localization of GhRbohD. (A) Subcellular localization of 35S::GhRbohD-GFP fusion proteins were transiently expressed in N. benthamiana leaves. (B,C) 35S::GhRbohD-GFP fusion proteins were transiently expressed in onion epidermal cells. The signal was visualized with confocal microscopy. Scale bar $=50 \mu \mathrm{m}$.

\subsection{GhPBL9 and GhRPL12C May Interact with GhRbohD in Cotton}

In order to explore the proteins that may interact with GhRbohD, two proteins GhPBL9 (Ghir_A10G022420) and GhRPL12C (Ghir_A09G015860) were investigated by Y2H. PBL9 is a serine threonine protein kinase, located in the mitochondria and cytoplasm membrane, and its main functions in Arabidopsis thaliana include ATP Bing and serine/threonine protein kinase activity. RPL12C is a 60s ribosomal protein, which is localized in the cytoplasm and ribosomes and is related to the coding translation of ribosomal large subunits. To further demonstrate the interaction between those two proteins and GhRbohD, we verified the interaction proteins. Firstly, the target protein, positive control, negative control and the interacting proteins were co-transformed into the yeast medium DDO (SD/-LeuTrp) and the colony growth was observed. Then the yeast rotation experiment of the interacting proteins was verified on the yeast medium QDO (SD/-Leu-Trp-His-Ade), and the interaction between GhPBL9 and GhRbohD, GhRPL12C and GhRbohD were all observed in $10^{-1}, 10^{-2}$ and $10^{-3}$ dilutions of yeast liquid (Figure 8 ). These results showed that GhPBL9 and GhRPL12C may interact with GhRbohD, and the protein interaction was stronger between GhRPL12C and GhRbohD than that between GhPBL9 and GhRbohD.

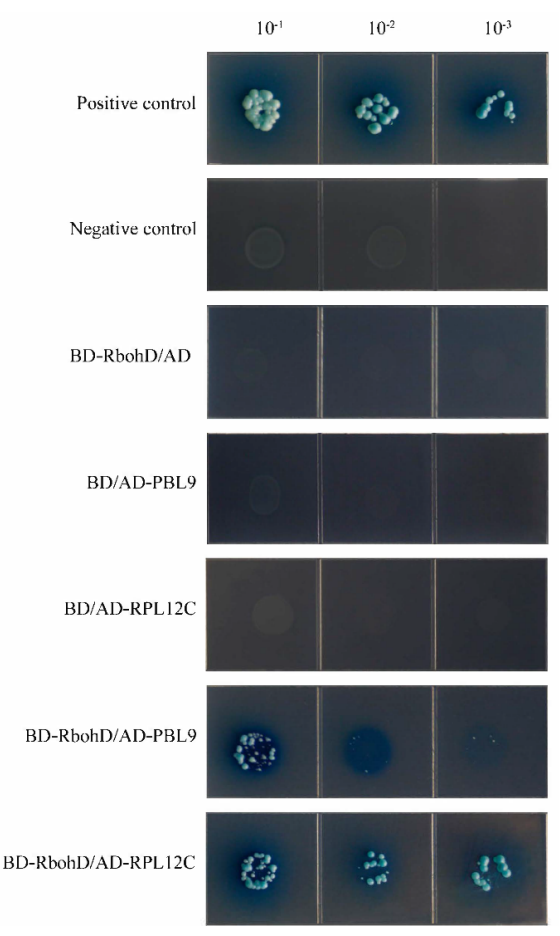

Figure 8. Yeast two-hybrid assays of the interactions of GhRbohD with GhPBL9 and GhRPL12C. Transformants were grown on SD/-Leu/-Trp/-Ade/-His (+X- $\alpha$-gal) media. pGBKT7-53/pGADT7RecT was used as the positive control. pGBKT7-Lam/pGADT7-RecT were used as negative controls. 


\section{Discussion}

Currently, Verticillium wilt of cotton caused by $V$. dahliae remains a heavy hindrance to cotton production, the main reason being lack of understanding of the mechanisms of effectively utilizing molecular and genetic engineering techniques to further develop resistant cultivars $[6,7]$. With in-depth application of technologies such as genome, transcriptome and protein modification (phosphorylation, ubiquitination, acetylation) to analyze cotton disease-resistance genes function and regulation mechanisms for Verticillium wilt, cotton disease-resistance research has made progress. In our previous study, a time-course phospho-proteomic analysis of roots of resistant and susceptible cotton lines in response to $V$. dahliae was performed, finding 30 early differentially expressed proteins, including GhCDPK28, GhCML41 and GhRbohD [24]. Notably, the phosphorylation levels of GhRbohD were significantly different between the resistant and susceptible varieties after inoculation with V. dahliae (Figure 2D). In addition, the expression level of GhRbohD gene was significantly increased when plants were infected with pathogen at $6 \mathrm{hpi}$, with upregulating of 50 times compared to the control, indicating that this gene may play an important role in the response of cotton to the stress of $V$. dahliae (Figure 2C). Numerous evidence has shown that the functional identification of earlier resistance genes was a promising way to prevent Verticillium wilt $[8,25]$. When plants were attacked by pathogens, this induced pathogen-associated molecular pattern (PAMP)-triggered immunity including ROS production, lignin and callose accumulation, elicitation of PR genes and hormone content changes [26,27]. In this study, the VIGS experiment showed that silencing GhRbohD in cotton, $\mathrm{ROS}$ production, $\mathrm{NO}$ and $\mathrm{H}_{2} \mathrm{O}_{2}$ contents were all significantly reduced (Figure 4). These results indicate that as an early disease-resistance gene, GhRbohD is involved in the prophase defense response of cotton against $V$. dahliae.

As a conserved signaling output during immunity across host plants and pathogens, ROS plays an important role in plant growth and development, with direct anti-microbial characteristics, but also serves as signaling molecule to activate the next immune response. Furthermore, different concentrations of ROS have a double-edged sword function in plants $[11,28,29]$. Although pathogen-induced ROS production has been documented for nearly 40 years [30], the detailed mechanism underpinning this activation remains largely unknown. Generally, ROS production is mediated by NADPH oxidase or rboh proteins, and a great deal of evidence clearly illustrates that RBOHD is mainly controlled by $\mathrm{Ca}^{2+}$ via direct binding to EF-hand motifs and phosphorylation by $\mathrm{Ca}^{2+}$-dependent protein kinases [16,31-33]. However, the functional analysis of RBOHD in cotton is far from adequate. In order to further clarify the relationship between ROS, GhRbohD and $\mathrm{Ca}^{2+}$ content, the in vitro experiment confirmed that the control plants had more ROS production than the GhRbohD-silenced plants, and $\mathrm{Ca}^{2+}$ concentration was also significantly higher than that of silent plants (Figure 4E), these results demonstrating the direct correlation between GhRbohD gene expression and $\mathrm{Ca}^{2+}$ concentration, which in turn supports that GhRbohD is regulated by $\mathrm{Ca}^{2+}$.

In plant immunity, rbohD plants over-accumulate salicylic acid, jasmonic acid and antimicrobial compounds upon pathogen attack, such as immune marker gene expression [34,35]. To further elucidate the effect of GhRbohD on Verticillium wilt resistance in cotton plants, qRT-PCR was employed to monitor the expression of disease-resistance genes. In GhRbohDsilenced plants, as key genes of the lignin metabolism pathway, GhCHI, GhPAL5 and GhC4H1 were significantly downregulated by varying degrees (Figure 5). Generally, the higher the lignin content of the plant, the stronger the resistance to pathogen challenge, especially vascular diseases [11,36]. Besides, GhJaz1, an important gene of the jasmonic acid pathway, showed significantly downregulated expression and reached its lowest value at $48 \mathrm{hpi}$, accounting for just one-sixth of that of the control. Collectively, these results indicate that ROS production mediated by GhRbohD could induce cotton to acquire local and systemic resistance by the lignin metabolism and jasmonic acid signaling pathways.

The identification of pathogens by plants triggers several early defense responses, including the production of ROS. RBOHs are major sources of ROS during plant pathogen 
interactions [37,38]. AtRbohD and AtRbohF were initially regarded as key components of plant defense mediated Arabidopsis disease resistance [39]. Further, AtRbohD-dependent $\mathrm{H}_{2} \mathrm{O}_{2}$ signaling was a critical modulator in the defense response against Vd-toxins, regulated by the PTPs-MPKs-WRKY pathway in Arabidopsis against V. dahliae [40]. In the current study, the results of the disease resistance test showed that GhRbohD-silenced cotton plants showed more serious symptoms than these of the control plants, and the DI value of GhRbohD-silenced plants was significantly increased by $53.16 \%$ compared to the control plants (Figure 3), accompanied by a significant reduction in $\mathrm{H}_{2} \mathrm{O}_{2}$ content. However, when $R b o h D$ overexpressed in Arabidopsis improving the resistance to $V$. dahliae, this reduced the infection of fungus in plant roots (Figure 4). In conclusion, these results strongly support that $R b o h D$ positively regulates the resistance of plants against $V$. dahliae. Furthermore, $\mathrm{Y} 2 \mathrm{H}$ assays was applied to screen the target proteins interacting with GhRbohD in cotton, to find that GhPBL9 and GhRPL12C may interact with GhRbohD. Notably, AtPBL9 is a serine threonine protein kinase with serine/threonine protein kinase activity, and the N-terminal of GhRbohD has four obviously phosphorylated sites; the specific phosphorylation activation process between GhRbohD and GhPBL9, and the mechanism of interaction proteins remain to be further explored.

\section{Materials and Methods}

\subsection{Plant Material and Growth Condition}

The cotton cultivar used in this experiment is Gossypium hirsutum L. (Zhongzhimian 2), which is resistant to $V$. dahliae, and cultivar Jimian 11 is susceptible to this pathogen. The introgression lines $\mathrm{BC}_{6} \mathrm{~F}_{3: 6}$ were generated from the advanced backcross and repeated using Zhongzhimian 2 as the recipient parent and Jimian 11 as the donor parent. Two materials NIL-R and NIL-S selected from the $\mathrm{BC}_{6} \mathrm{~F}_{3: 6}$ population were resistant and susceptible to Verticillium wilt, respectively [24]. Cotton plants for virus-induced gene silencing (VIGS) analysis were cultured in the bottomless paper pot for $V$. dahliae infection, grown in the greenhouse at $28^{\circ} \mathrm{C}$ with a $16 \mathrm{~h} / 8 \mathrm{~h}$ light $/$ dark photoperiod.

Tobacco (Nicotiana benthamiana) seedlings were grown in a greenhouse at $25^{\circ} \mathrm{C}$ under a $16 \mathrm{~h} / 8 \mathrm{~h}$ light/dark photoperiod for GhRbohD gene subcellular localization. Arabidopsis thaliana were grown in a $23-25^{\circ} \mathrm{C}$ greenhouse with a $16 \mathrm{~h} / 8 \mathrm{~h}$ light cycle.

\subsection{Fungal Strain and Growth Condition}

The strong pathogenic defoliating $V$. dahliae strain Vd080 was cultured on potato dextrose agar (PDA) medium at $25^{\circ} \mathrm{C}$ for 5 days. Then, this fungus was cultured in liquid Czapek-Dox media at $25^{\circ} \mathrm{C}$ for 5 days, and the conidia was collected. The final concentration of the spore suspension was adjusted to $1 \times 10^{7} \mathrm{CFU} / \mathrm{mL}$ with sterile water [41].

\subsection{Gene Cloning and Bioinformatic Analyses}

Total RNA was extracted from cotton roots using the RNAprep Pure Plant Plus Kit (Tiangen, Beijing, China) according to the manufacturer's instructions. TransScript ${ }^{\circledR}$ Allin-One first-strand cDNA Synthesis SuperMix for reverse transcription kit was used to synthesize cDNA. The amplified product was cloned into the $\mathrm{p} E A S{ }^{\circledR}$-Blunt Cloning Kit vector, and confirmed by sequencing. The cloning primers (GhRbohD-full-F/R) and other primers mentioned below are listed in Supplementary Table S1.

The amino acid sequence alignment and phylogenetic relationship analysis were performed on ClustalX2.1 and MEGAX, respectively [42,43]. A total of Rbohs gene sequences were downloaded from TAIR and the COTTON database. Multiple sequence alignments of all identified Rbohs from cotton and Arabidopsis were performed in ClustalX2.1. The phylogenetic tree of deduced amino acid sequences was constructed by applying the neighbor-joining method. To analyze the exon-intron distributions of the Rbohs gene, the gene structure display server (GSDS) was utilized. Next, conserved motifs were predicted using the MEME9 tool [44]. The positional information of a given cot- 
ton Rbohs was obtained from parsed general feature format (GFF) files, and downloaded from the Cotton Gene website. The Rbohs in Gossypium species genomes were all mapped onto the chromosomes used the TBtools software [45]. The promoter sequences of Rbohs family genes were extracted and upload to PlantCARE database ( http://bioinformatics.psb.ugent.be/webtools/plantcare/html/ (accessed on 8 August 2021)) for prediction of cis-acting elements. The cis-acting elements distribution upon promoters of OPR genes were displayed by GSDS v2.0 [46]. To detect expression pattern of GhRbohD gene, we analysed the transcriptome data of Rbohs family in G. hirsutum from https:/ / cottonfgd.org/ (accessed on 12 August 2021).

\subsection{Virus-Induced Gene Silencing (VIGS)}

The specific fragments of the GhRbohD and positive control gene PDS were amplified by PCR, digested with BamH I and Kpn I and then cloned into the tobacco rattle virus (TRV) vector pYL156 to generate pYLRbohD and pYLPDS vectors. The vectors pYL156, pYLRbohD, pYLPDS and auxiliary vector pYL192 were transformed into Agrobacterium tumefaciens strain GV3101 and cultured in LB medium with $50 \mu \mathrm{g} / \mathrm{mL}$ kanamycin, $30 \mu \mathrm{g} / \mathrm{mL}$ gentamicin sulphate and $40 \mu \mathrm{g} / \mathrm{mL}$ rifampicin at $28^{\circ} \mathrm{C}$ for $2-3$ days. Then the Agrobacterium cells were resuspended in MMA solution (10 mM N-morpholino ethanesulfonic acid, $10 \mathrm{mM} \mathrm{MgCl}_{2}$, and $200 \mathrm{mM}$ acetoyringone) and adjusted to 1.2 value of $\mathrm{OD}_{600}$. The Agrobacterium cells containing the aforementioned vectors were equally mixed with those containing pYL192 and were incubated at room temperature for $3 \mathrm{~h}$ in darkness [47]. Finally, a needleless syringe was used to inject the mixed bacterial solution into the back of 7-days-old cotton cotyledon. The experiment was performed three times, and each sample comprised of more than 50 cotyledons.

After the albino phenotype appeared in the positive control plants, the successfully silenced plants were inoculated with the $V$. dahliae strain $\mathrm{Vd} 080$ at conidia suspension $\left(1 \times 10^{7} \mathrm{CFU} / \mathrm{mL}\right)$ by the root dipping method for $10 \mathrm{~min}$ and then replanted into soil.

\section{5. qRT-PCR Analysis}

The cotton leaf RNA extraction and reversed transcription into cDNA method referred to the above. Quantitative real-time PCR was performed using the LightCycler 480 System. A $20 \mu \mathrm{L}$ reaction mixture containing diluted cDNA and TB Green Premix Ex Taq ${ }^{\mathrm{TM}}$ II (Tli RNaseH Plus) was used for qRT-PCR following the procedure: $94^{\circ} \mathrm{C}$ for $2 \mathrm{~min}$, followed by 45 cycles of $94{ }^{\circ} \mathrm{C}$ for $15 \mathrm{~s}, 55^{\circ} \mathrm{C}$ for $15 \mathrm{~s}$ and $72{ }^{\circ} \mathrm{C}$ for $20 \mathrm{~s}$. qRT-PCR was performed to quantify the transcript levels of several disease resistance-related genes, with $U B Q$ gene as internal control [48]. The expression assays were repeated three times and each assay was performed with three independent technical repeats. The relative expression levels of genes were calculated using the $2^{-\Delta \Delta \mathrm{Ct}}$ method [49].

\subsection{Plant Disease Resistance Assess}

A scale of $0-4$ was used to classify plants including GhRbohD gene silenced cotton and transgenic Arabidopsis according to the percentage of plant tissue affected by chlorosis, leaf necrosis or defoliation (0: no symptoms, $1: \leq 33 \%, 2:>33 \%$ and $\leq 66 \%, 3:>66 \%$ and $\leq 99 \%$, 4: $\geq 99 \%$ leaves with chlorosis wilt symptoms). The disease index (DI) was calculated as previously described, $D I=\left[\left(0 n_{0}+1 n_{1}+2 n_{2}+3 n_{3}+4 n_{4}\right) / 4 n\right] \times 100$, where $n_{0}-n_{4}$ were the numbers of plants with each of the corresponding disease ratings, and $\mathrm{n}$ was the total number of plants assessed [50]. Futhermore, $V$. dahliae recovery assay was applicated to determine the effects of $V$. dahliae infection on cotton plants.

\subsection{Observation of ROS, Lignin Synthesis and Callose Accumulation}

To verify ROS by observing the accumulation of $\mathrm{H}_{2} \mathrm{O}_{2}$, the leaves from the control and GhRbohD-silenced cotton plants were collected at $24 \mathrm{~h}, 48 \mathrm{~h}$ after inoculation with $V$. dahliae Vd080. After incubation in a large centrifuge tube with an appropriate amount of 3 , 3-Diaminobenzidime (DAB, $1 \mathrm{mg} / \mathrm{mL}, \mathrm{pH} 7.5)$ at room temperature in darkness for $8 \mathrm{~h}$, 
leaves were decolorized in $95 \%$ ethanol for $2 \mathrm{~min}$, followed by decolorizatiion in absolute ethanol until the green of the leaves was completely removed. Then accumulation of $\mathrm{H}_{2} \mathrm{O}_{2}$ of leaves was observed under a microscope in $70 \%$ glycerol $[51,52]$.

Lignification of the control and GhRbohD-silenced plants was examined with phloroglucinol staining. Root sections of cotton seedlings were incubated in $10 \%$ phloroglucinol solution for $2 \mathrm{~min}$. The samples were then incubated in concentrated $\mathrm{H}_{2} \mathrm{SO}_{4}$ for a moment, and the staining signals were observed using a microscope [5].

Callose staining used the true leaves of the control and GhRbohD-silenced cotton. Leaves were fixed in fixative solution (ethanol: acetic acid $=3: 1$ ) for $2 \mathrm{~h}$ to remove chlorophyll, then soaked in $70 \%$ and $50 \%$ ethanol for $2 \mathrm{~h}$, respectively, and put in water overnight. After rinsing the leaves with water, they were treated in $10 \% \mathrm{NaOH}$ for $1 \mathrm{~h}$ to make them transparent. The callose content was observed under a fluorescent microscope with UV excitation light after being cultured in darkness in $0.01 \%$ aniline blue for $3 \mathrm{~h} \mathrm{[5].} \mathrm{Each}$ experiment was repeated three times.

\subsection{Visualization of $\mathrm{H}_{2} \mathrm{O}_{2}, \mathrm{NO}$ and $\mathrm{Ca}^{2+}$}

A Quantitative Assay Kit (Nanjing Jiancheng, Beijing, China) was used for the determination of $\mathrm{H}_{2} \mathrm{O}_{2}$ and nitric oxide (NO) in the control and GhRbohD-silenced cotton plants, referring to the manual for detailed operation steps.

The calcium content of the control and GhRbohD-silenced plants' leaves were determined with a Calcium Colorimetric Assay Kit (Nanjing Jiancheng, Beijing, China). The samples' absorbance was measured at $575 \mathrm{~nm}$, and the concentrations of calcium were calculated based on the formula: $C=S_{a} / S_{v}\left(S_{a}\right.$ : amount of calcium in unknown sample $(\mu \mathrm{g})$ from standard curve; $\mathrm{S}_{\mathrm{v}}$ : sample volume $(\mu \mathrm{L})$ added into the wells; C: concentration of calcium in sample). Three independent biological and technical repeats were performed.

\subsection{Subcellular Localization}

The full-length coding sequence of GhRbohD (without stop codon) was inserted into the overexpression vector $\mathrm{pC} A M B I A 3300$ with GFP tag to construct the transient expression vector GhRbohD-GFP. Then it was transformed into Agrobacterium tumefaciens GV3101. The mixture of GV3101 bacteria solution of GhRbohD-GFP and buffer solution were injected into the leaves of 3-weeks-old tobacco plants at the stage of 4-5 leaves with a syringe. Then the tobacco was cultured in darkness for $24 \mathrm{~h}$ and then transferred to normal conditions for $24 \mathrm{~h}$. Finally, the fluorescence in the leaves could be observed with a laser confocal microscope [8].

\subsection{Arabidopsis thaliana Transformation}

The full length CDs of GhRbohD were cloned by using cotton cDNA as template, and the GhRbohD gene fragment was connected to the pCAMBIA2300 vector with a $35 S$ strong promoter by digesting the sequence with cision enzyme. Next, the recombinant plasmid was transformed into Agrobacterium tumefaciens GV3101 with the freeze thaw method. The overexpression vector was transformed into $A$. thaliana $\mathrm{Col}-0$ via the floral dip method. The transformants $\left(T_{0}, T_{1}\right.$ and $T_{2}$ seeds) were screened for survival on a half concentration of MS medium containing $50 \mathrm{mg} / \mathrm{L}$ kanamycin. $T_{3}$ transgenic plants were identified with qRT-PCR analysis.

The seeds of $\mathrm{T}_{3}$ transgenic lines were inoculated on medium (1/2 MS), and after these seedlings were grown for about two weeks, the roots were directly inoculated with $5 \mu \mathrm{L}$ Vd080 conidia suspension $\left(1 \times 10^{7} \mathrm{CFU} / \mathrm{mL}\right)$ [53]. Then Arabidopsis thaliana were cultured in the soil for disease resistance identification.

\subsection{Yeast Two-Hybrid Assays (Y2H)}

The GhRbohD cDNA was amplified using the primer pair GhRbohD-BD-F/R. PCRamplified fragments were cloned in-frame with GAL4BD in the vector pGBKT7. BDGhRbohD was introduced into the yeast strain Y2HGold. The cDNA library was con- 
structed from upland cotton roots inoculated with $V$. dahliae, aimed to $\mathrm{Y} 2 \mathrm{H}$ screen with BD Matched maker Library Construction \& Screening Kits (Clontech). Then they were co-transferred into yeast receptive cells and cultured on the DDO (SD/-Leu-Trp) culture medium for one to two weeks. If there were any clones, these were transferred to the QDO (SD/-His-Leu-Trp-Ade) medium for verification.

\section{Conclusions}

From our previous study, we found early differentially expressed protein GhRbohD by phospho-proteomic analysis, which responded to plant defenses against pathogens. In this study, the phylogenetic and structural analysis of Rbohs by bioinformatics analysis indicated that the Rbohs family was conserved in cotton and A. thaliana plants. In detail, there were 12 members of RbohD out of 57 Rbohs in cotton. VIGS test demonstrated that ROS production, NO, $\mathrm{H}_{2} \mathrm{O}_{2}$ and $\mathrm{Ca}^{2+}$ contents of $G h R b o h D$-silenced cotton plants were significantly reduced, as the same as lignin synthesis and callose accumulation. In addition, expression profile analysis showed that GhCHI, GhPAL5, GhC4H1 and GhJaz1 were significantly downregulated, involving the lignin metabolism and jasmonic acid signaling pathways. Further investigation showed that the overexpressed Arabidopsis exhibited stronger resistance. In conclusion, these results provide evidence of the role of GhRbohD mediated ROS production, confirming the positive regulation of GhRbohD in plants against $V$. dahliae.

Supplementary Materials: The following are available online at https:/ /www.mdpi.com/article/10 .3390/ijms222313041/s1.

Author Contributions: W.H., Y.Z., H.F. and H.Z. designed the experiment; J.Z. performed the bioinformatics analysis; W.H. and Y.Z. analyzed the results and prepared the manuscript; H.F., H.Z., Z.F., F.W., L.Z. and Y.S. revised the manuscript. All authors have read and agreed to the published version of the manuscript.

Funding: This work was supported by the Natural Science Foundation of Henan Province (No. 212300410418), the Central Public-interest Scientific Institution Basal Research Fund (No. 16101620 21031) and the Agricultural Science and Technology Innovation Program of Chinese Academy of Agricultural Sciences.

Institutional Review Board Statement: Not applicable.

Informed Consent Statement: Not applicable.

Data Availability Statement: The data used to support the findings of this study are available from the corresponding author upon request.

Conflicts of Interest: The authors declare no conflict of interest.

\section{References}

1. Yang, Z.; Qanmber, G.; Wang, Z.; Yang, Z.; Li, F. Gossypium Genomics: Trends, Scope, and Utilization for Cotton Improvement. Trends Plant Sci. 2020, 25, 488-500. [CrossRef] [PubMed]

2. Zhang, J.; Sanogo, S.; Flynn, R.; Baral, J.B.; Bajaj, S.; Hughs, S.E.; Percy, R.G. Germplasm evaluation and transfer of Verticillium wilt resistance from Pima (Gossypium barbadense) to Upland cotton (G. hirsutum). Euphytica 2011, 187, 147-160. [CrossRef]

3. Ayele, A.; Wheeler, T.; Dever, J. Gossypium hirsutum impacts of Verticillium wilt on photosynthesis rate, lint production, and fiber quality of greenhouse-grown Cotton. Plants 2020, 9, 857. [CrossRef]

4. Fradin, E.; Thomma, B. Physiology and molecular aspects of Verticillium wilt diseases caused by V. dahliae and V. albo-atrum. Mol. Plant Pathol. 2006, 7, 71-86. [CrossRef] [PubMed]

5. Zhou, J.; Feng, Z.; Liu, S.; Wei, F.; Shi, Y.; Zhao, L.; Huang, W.; Zhou, Y.; Feng, H.; Zhu, H. CGTase, a novel antimicrobial protein from Bacillus cereus YUPP-10, suppresses Verticillium dahliae and mediates plant defence responses. Mol. Plant Pathol. 2021, 22, 130-144. [CrossRef]

6. Shaban, M.; Miao, Y.; Ullah, A.; Khan, A.Q.; Menghwar, H.; Khan, A.H.; Ahmed, M.M.; Tabassum, M.A.; Zhu, L. Physiological and molecular mechanism of defense in cotton against Verticillium dahliae. Plant Physiol. Biochem. 2018, 125, 193-204. [CrossRef]

7. Song, R.; Li, J.; Xie, C.; Jian, W.; Yang, X. An Overview of the Molecular Genetics of Plant Resistance to the Verticillium Wilt Pathogen Verticillium dahliae. Int. J. Mol. Sci. 2020, 21, 1120. [CrossRef] [PubMed] 
8. Zhang, X.; Feng, Z.; Zhao, L.; Liu, S.; Wei, F.; Shi, Y.; Feng, H.; Zhu, H. Succinate dehydrogenase SDH1-1 positively regulates cotton resistance to Verticillium dahliae through a salicylic acid pathway. J. Cotton Res. 2020, 3, 1-12. [CrossRef]

9. Choudhury, S.; Panda, P.; Sahoo, L.; Panda, S.K. Reactive oxygen species signaling in plants under abiotic stress. Plant Signal. Behav. 2013, 8, e23681. [CrossRef]

10. Suzuki, N.; Katano, K. Coordination Between ROS Regulatory Systems and Other Pathways Under Heat Stress and Pathogen Attack. Front. Plant Sci. 2018, 9, 490. [CrossRef]

11. Torres, M.A.; Dangl, J.L. Functions of the respiratory burst oxidase in biotic interactions, abiotic stress and development. Curr. Opin. Plant Biol. 2005, 8, 397-403. [CrossRef]

12. Kehrer, J.P. The Haber-Weiss reaction and mechanisms of toxicity. Toxicology 2000, 149, 43-50. [CrossRef]

13. Kaya, H.; Takeda, S.; Kobayashi, M.; Kimura, S.; Iizuka, A.; Imai, A.; Hishinuma, H.; Kawarazaki, T.; Mori, K.; Yamamoto, Y.; et al. Comparative analysis of the reactive oxygen species-producing enzymatic activity of Arabidopsis NADPH oxidases. Plant J. 2018, 98, 291-300. [CrossRef] [PubMed]

14. Sumimoto, H. Structure, regulation and evolution of Nox-family NADPH oxidases that produce reactive oxygen species. FEBS J. 2008, 275, 3249-3277. [CrossRef]

15. Kadota, Y.; Shirasu, K.; Zipfel, C. Regulation of the NADPH Oxidase RBOHD During Plant Immunity. Plant Cell Physiol. 2015, 56, 1472-1480. [CrossRef] [PubMed]

16. Kadota, Y.; Sklenar, J.; Derbyshire, P.; Stransfeld, L.; Asai, S.; Ntoukakis, V.; Jones, J.; Shirasu, K.; Menke, F.; Jones, A.; et al. Direct Regulation of the NADPH Oxidase RBOHD by the PRR-Associated Kinase BIK1 during Plant Immunity. Mol. Cell 2014, 54, 43-55. [CrossRef] [PubMed]

17. Suzuki, N.; Miller, G.; Morales, J.; Shulaev, V.; Torres, M.A.; Mittler, R. Respiratory burst oxidases: The engines of ROS signaling. Curr. Opin. Plant Biol. 2011, 14, 691-699. [CrossRef] [PubMed]

18. Miller, G.; Schlauch, K.; Tam, R.; Cortes, D.; Torres, M.A.; Shulaev, V.; Dangl, J.L.; Mittler, R. The Plant NADPH Oxidase RBOHD Mediates Rapid Systemic Signaling in Response to Diverse Stimuli. Sci. Signal. 2009, 2, ra45. [CrossRef]

19. Marino, D.; Dunand, C.; Puppo, A.; Pauly, N. A burst of plant NADPH oxidases. Trends Plant Sci. 2012, 17, 9-15. [CrossRef]

20. Li, L.; Li, M.; Yu, L.; Zhou, Z.; Liang, X.; Liu, Z.; Cai, G.; Gao, L.; Zhang, X.; Wang, Y.; et al. The FLS2-Associated Kinase BIK1 Directly Phosphorylates the NADPH Oxidase RbohD to Control Plant Immunity. Cell Host Microbe 2014, 15, 329-338. [CrossRef]

21. Xu, W.; Wang, Y. Post-translational Modifications of Serine/Threonine and Histidine Kinases and Their Roles in Signal Transductions in Synechocystis Sp. PCC 6803. Appl. Biochem. Biotechnol. 2021, 193, 687-716. [CrossRef] [PubMed]

22. Lee, D.; Lal, N.; Lin, Z.-J.D.; Ma, S.; Liu, J.; Castro, B.; Toruño, T.; Dinesh-Kumar, S.P.; Coaker, G. Regulation of reactive oxygen species during plant immunity through phosphorylation and ubiquitination of RBOHD. Nat. Commun. 2020, 11, 1-16. [CrossRef]

23. Zhang, T. En Garde: CRK2 Preassociates with RBOHD and Regulates ROS Production. Plant Cell 2020, 32, 801-802. [CrossRef] [PubMed]

24. Zhang, Y.; Shi, Y.; Zhao, L.; Wei, F.; Feng, Z.; Feng, H. Phosphoproteomics Profiling of Cotton (Gossypium hirsutum L.) Roots in Response to Verticillium dahliae Inoculation. ACS Omega 2019, 4, 18434-18443. [CrossRef]

25. Beliën, T.; Van Campenhout, S.; Robben, J.; Volckaert, G. Microbial Endoxylanases: Effective Weapons to Breach the Plant Cell-Wall Barrier or, Rather, Triggers of Plant Defense Systems? Mol. Plant-Microbe Interact. 2006, 19, 1072-1081. [CrossRef]

26. Norman, C.; Howell, K.A.; Millar, A.H.; Whelan, J.M.; Day, D.A. Salicylic Acid Is an Uncoupler and Inhibitor of Mitochondrial Electron Transport. Plant Physiol. 2004, 134, 492-501. [CrossRef]

27. Moreau, M.; Tian, M.; Klessig, D.F. Salicylic acid binds NPR3 and NPR4 to regulate NPR1-dependent defense responses. Cell Res. 2012, 22, 1631-1633. [CrossRef]

28. Apel, K.; Hirt, H. Reactive oxygen species: Metabolism, oxidative stress, and signal transduction. Annu. Rev. Plant Biol. 2004, 55, 373-399. [CrossRef] [PubMed]

29. Mittler, R.; Vanderauwera, S.; Suzuki, N.; Miller, G.; Tognetti, V.B.; Vandepoele, K.; Gollery, M.; Shulaev, V.; Van Breusegem, F. ROS signaling: The new wave? Trends Plant Sci. 2011, 16, 300-309. [CrossRef]

30. Doke, N. Generation of superoxide anion by potato tuber protoplasts during the hypersensitive response to hyphal wall components of Phytophthora infestans and specific inhibition of the reaction by suppressors of hypersensitivity. Physiol. Plant Pathol. 1983, 23, 359-367. [CrossRef]

31. Kadota, Y.; Goh, T.; Tomatsu, H.; Tamauchi, R.; Higashi, K.; Muto, S.; Kuchitsu, K. Cryptogein-induced initial events in tobacco BY-2 cells: Pharmacological characterization of molecular relationship among cytosolic $\mathrm{Ca}(2+)$ transients, anion efflux and production of reactive oxygen species. Plant Cell Physiol. 2004, 45, 160-170. [CrossRef] [PubMed]

32. Lecourieux, D.; Ranjeva, R.; Pugin, A. Calcium in plant defence-signalling pathways. New Phytol. 2006, 171, 249-269. [CrossRef]

33. Segonzac, C.; Zipfel, C. Activation of plant pattern-recognition receptors by bacteria. Curr. Opin. Microbiol. 2011, 14, 54-61. [CrossRef]

34. Pogany, M.; von Rad, U.; Grun, S.; Dongó, A.; Pintye, A.; Simoneau, P.; Bahnweg, G.; Kiss, L.; Barna, B.; Durner, J. Dual Roles of Reactive Oxygen Species and NADPH Oxidase RBOHD in an Arabidopsis-Alternaria Pathosystem. Plant Physiol. 2009, 151, 1459-1475. [CrossRef]

35. Chaouch, S.; Queval, G.; Noctor, G. AtRbohF is a crucial modulator of defence-associated metabolism and a key actor in the interplay between intracellular oxidative stress and pathogenesis responses in Arabidopsis. Plant J. 2012, 69, 613-627. [CrossRef] [PubMed] 
36. Sun, Q.; Jiang, H.; Zhu, X.; Wang, W.; He, X.; Shi, Y.; Cai, Y. Analysis of sea-island cotton and upland cotton in response to Verticillium dahliae infection by RNA sequencing. BMC Genom. 2013, 14, 1-13. [CrossRef]

37. Kwak, J.M.; Mori, I.C.; Pei, Z.-M.; Leonhardt, N.; Torres, M.A.; Dangl, J.L.; Bloom, R.E.; Bodde, S.; Jones, J.; Schroeder, J. NADPH oxidase AtrbohD and AtrbohF genes function in ROS-dependent ABA signaling in Arabidopsis. EMBO J. 2003, 22, $2623-2633$. [CrossRef] [PubMed]

38. Zandalinas, S.I.; Fichman, Y.; Mittler, R. Vascular Bundles Mediate Systemic Reactive Oxygen Signaling during Light Stress. Plant Cell 2020, 32, 3425-3435. [CrossRef] [PubMed]

39. Torres, M.A.; Jones, J.D.G.; Dangl, J.L. Pathogen-induced, NADPH oxidase-derived reactive oxygen intermediates suppress spread of cell death in Arabidopsis thaliana. Nat. Genet. 2005, 37, 1130-1134. [CrossRef] [PubMed]

40. Zhao, J.; Chen, Q.; Zhou, S.; Sun, Y.; Li, X.; Li, Y. H2Bub1 regulates RbohD-dependent hydrogen peroxide signal pathway in the defense responses to Verticillium dahliae toxins. Plant Physiol. 2020, 182, 640-657. [CrossRef]

41. Liu, S.; Sun, R.; Zhang, X.; Feng, Z.; Wei, F.; Zhao, L.; Zhang, Y.; Zhu, L.; Feng, H.; Zhu, H. Genome-Wide Analysis of OPR Family Genes in Cotton Identified a Role for GhOPR9 in Verticillium dahliae Resistance. Genes 2020, 11, 1134. [CrossRef] [PubMed]

42. Edgar, R.C. MUSCLE: Multiple sequence alignment with high accuracy and high throughput. Nucleic Acids Res. 2004, 32, 1792-1797. [CrossRef]

43. Kumar, S.; Stecher, G.; Li, M.; Knyaz, C.; Tamura, K. MEGA X: Molecular Evolutionary Genetics Analysis across Computing Platforms. Mol. Biol. Evol. 2018, 35, 1547-1549. [CrossRef] [PubMed]

44. Chang, Y.; Li, B.; Shi, Q.; Geng, R.; Geng, S.; Liu, J.; Zhang, Y.; Cai, Y. Comprehensive analysis of respiratory burst oxidase homologs (Rboh) gene family and function of GbRboh5/18 on Verticillium wilt resistance in Gossypium barbadense. Front. Genet. 2020, 11. [CrossRef] [PubMed]

45. Chen, C.; Chen, H.; He, Y.; Xia, R. TBtools, a toolkit for biologists integrating various biological data handling tools with a user-friendly interface. BioRxiv 2018, 289660. [CrossRef]

46. Hu, B.; Jin, J.; Guo, A.-Y.; Zhang, H.; Luo, J.; Gao, G. GSDS 2.0: An upgraded gene feature visualization server. Bioinformatics 2015, 31, 1296-1297. [CrossRef]

47. Tang, Y.; Zhang, Z.; Lei, Y.; Hu, G.; Liu, J.; Hao, M.; Chen, A.; Peng, Q.; Wu, J. Cotton WATs Modulate SA Biosynthesis and Local Lignin Deposition Participating in Plant Resistance Against Verticillium dahliae. Front. Plant Sci. 2019, 10, 526. [CrossRef]

48. Cheng, X.-X.; Zhao, L.-H.; Klosterman, S.J.; Feng, H.-J.; Feng, Z.-L.; Wei, F.; Shi, Y.-Q.; Li, Z.-F.; Zhu, H.-Q. The endochitinase VDECH from Verticillium dahliae inhibits spore germination and activates plant defense responses. Plant Sci. 2017, $259,12-23$. [CrossRef] [PubMed]

49. Hu, Q.; Min, L.; Yang, X.; Jin, S.; Zhang, L.; Li, Y.; Ma, Y.; Qi, X.; Li, D.; Liu, H.; et al. Laccase GhLac1 Modulates Broad-Spectrum Biotic Stress Tolerance via Manipulating Phenylpropanoid Pathway and Jasmonic Acid Synthesis. Plant Physiol. 2018, 176, 1808-1823. [CrossRef]

50. Yuan, Y.; Feng, H.; Wang, L.; Li, Z.; Shi, Y.; Zhao, L.; Feng, Z.; Zhu, H. Potential of Endophytic Fungi Isolated from Cotton Roots for Biological Control against Verticillium Wilt Disease. PLoS ONE 2017, 12, e0170557. [CrossRef]

51. Hu, Q.; Zhu, L.; Zhang, X.; Guan, Q.; Xiao, S.; Min, L.; Zhang, X. GhCPK33 Negatively Regulates Defense against Verticillium dahliae by Phosphorylating GhOPR3. Plant Physiol. 2018, 178, 876-889. [CrossRef]

52. Thordal-Christensen, H.; Zhang, Z.; Wei, Y.; Collinge, D.B. Subcellular localization of H2O2 in plants. H2O2 accumulation in papillae and hypersensitive response during the barley-powdery mildew interaction. Plant J. 1997, 11, 1187-1194. [CrossRef]

53. Gong, Q.; Yang, Z.; Wang, X.; Butt, H.I.; Chen, E.; He, S.; Zhang, C.; Zhang, X.; Li, F. Salicylic acid-related cotton (Gossypium arboreum) ribosomal protein GaRPL18 contributes to resistance to Verticillium dahliae. BMC Plant Biol. 2017, 17, 1-15. [CrossRef] 